\title{
Tongguan capsule ameliorates coronary artery stenosis in a 40 -year-old woman
}

\author{
This article was published in the following Dove Press journal: \\ Drug Design, Development and Therapy \\ 10 August 2015 \\ Number of times this article has been viewed
}

\author{
Huan $\mathrm{Ma}^{\prime}$ \\ Lei Wang' \\ Daozheng Huang ${ }^{2}$ \\ Guoqing Liu ${ }^{3}$ \\ Minzhou Zhang' \\ 'Department of Critical Care \\ Medicine, Guangdong Provincial \\ Hospital of Chinese Medicine, \\ ${ }^{2}$ Department of Critical Care \\ Medicine, Guangdong General \\ Hospital, ${ }^{3}$ Medical Imaging Central, \\ Guangdong Provincial Hospital \\ of Chinese Medicine, Guangzhou, \\ Guangdong, People's Republic of \\ China
}

\begin{abstract}
Cardiovascular disease is the leading cause of death worldwide, with coronary heart disease as the major contributor to this related mortality. There is a growing trend in the application of Chinese medicine in clinical practice for the treatment of coronary heart disease. However, there is a lack of knowledge surrounding the pharmacological, toxicological, and biological profiles of Chinese medicine. In this case report, we describe the therapeutic effects of Tongguan capsule in a 40-year-old woman diagnosed with stable angina pectoris. To the best of the authors' knowledge, this is the first case documented of the therapeutic effect of Tongguan capsule in the treatment of coronary heart disease.
\end{abstract}

Keywords: Chinese medicine, Tongguan capsule, cardiovascular disease, stable angina pectoris

\section{Introduction}

Cardiovascular disease (CVD) is the leading cause of death globally, with an estimated 17.5 million deaths in 2012 , accounting for $31 \%$ of all deaths that year. ${ }^{1-3}$ Of the 17.5 million deaths, approximately 7.4 million resulted from coronary heart disease (CHD), the leading cause of CVD mortality. ${ }^{1,2}$ In the US, CHD caused approximately one out of every seven deaths in 2011, with an estimated 635,000 new cases of heart attack and approximately 300,000 cases of recurrent attack in the US each year. ${ }^{1,2}$ In the People's Republic of China, there are approximately 230 million people who have CVD. In 2010, an estimated 154.8 per 100,000 deaths in urban areas, and 163.1 per 100,000 deaths in rural areas of People's Republic of China, were related to CVDs. ${ }^{4}$ Due to the high mortality rate of CVDs, it is of great importance to explore new therapeutics to curb the development and progression of CVDs in clinical practice, including Chinese medicine.

There is a growing number of studies which have found that Chinese herbal medicines have been shown to exert protective cardiovascular effects in both preclinical and clinical settings. ${ }^{5-7}$ Danshen (Salvia miltiorrhiza), and Danshen products, for example, have been predominantly used for the treatment of CVD, due to its various pharmacological activities eg, improving microcirculation, causing coronary vasodilatation, suppressing the formation of thromboxane, inhibiting platelet adhesion and aggregation, and protecting against myocardial ischemia. ${ }^{8-10}$ Tongguan capsule (TGC) is a Chinese herbal medicine made from the powder mixture of Radix astragali, S. miltiorrhiza, hirudin, and borneol, which exhibit healing qualities of tonifying Qi and activating blood. However, the pharmacokinetics, pharmacodynamics, toxicity, mechanism of action, and the therapeutic target of TGC are still unclear.

In this paper, we report on the case of a 40-year-old woman suffering from chest pains for 1 month and the therapeutic effect of TGC. The patient was diagnosed with stable angina pectoris and took TGC for 10 months. To the best of our knowledge, no 
case of therapeutic effect of TGC in patients with CHD has been described in literature until now.

\section{Case report}

In October 2013, a 40-year-old woman sought medical advice from Guangdong Provincial Hospital of Chinese Medicine with a complaint of atypical chest pain, which had been ongoing for 1 month. She had no diabetes, hypertension, or obesity, was a nonsmoker, and had no family history of CVD. On arrival, her blood pressure was 122/73 $\mathrm{mmHg}$, and heart rate was 71 beats per minute. The laboratory examination on admission showed that her low-density lipoprotein cholesterol (LDL-C) level was $2.1 \mathrm{mmol} / \mathrm{L}$, and non-highdensity lipoprotein cholesterol (non-HDL-C) level was $2.89 \mathrm{mmol} / \mathrm{L}$. The 24-hour electrocardiogram results showed a sinus rhythm and ST-T segment depression when the heart beats $>120 \mathrm{bpm}$. Ultracardiography results showed a normal cardiac function with the ejection fraction at $72 \%$ and mild tricuspid regurgitation. The coronary computed tomography
(CT) scan demonstrated that the first diagonal branch of the left coronary artery was approximately $50 \%$ stenosis, and the atherosclerotic plaque was non-calcified (Figure $1 \mathrm{~A}$ and B).

The woman was diagnosed with stable angina pectoris and was recommended to take aspirin and statin, which are the second most common prevention drugs for CHD. ${ }^{11,12}$ However, the women rejected these Western drugs, due to the concern of side effects. The patient preferred to take traditional Chinese medicine (TCM), including Chinese herbs and Chinese patent medicine. After careful examination of her symptoms, including tongue condition and pulse condition, the woman's TCM syndrome-type was diagnosed as Qi deficiency and blood stasis. According to her syndrome type, TGC was prescribed to her. This study was approved by the ethics committee of Guangdong Provincial Hospital of Chinese Medicine.

After administration of TGC 4 tablets of TGC each time, 3 times per day for 2 months, the patients chest pain became less frequent, and 6 months later, she had no chest pain at all. The patient continued to take TGC for 10 months
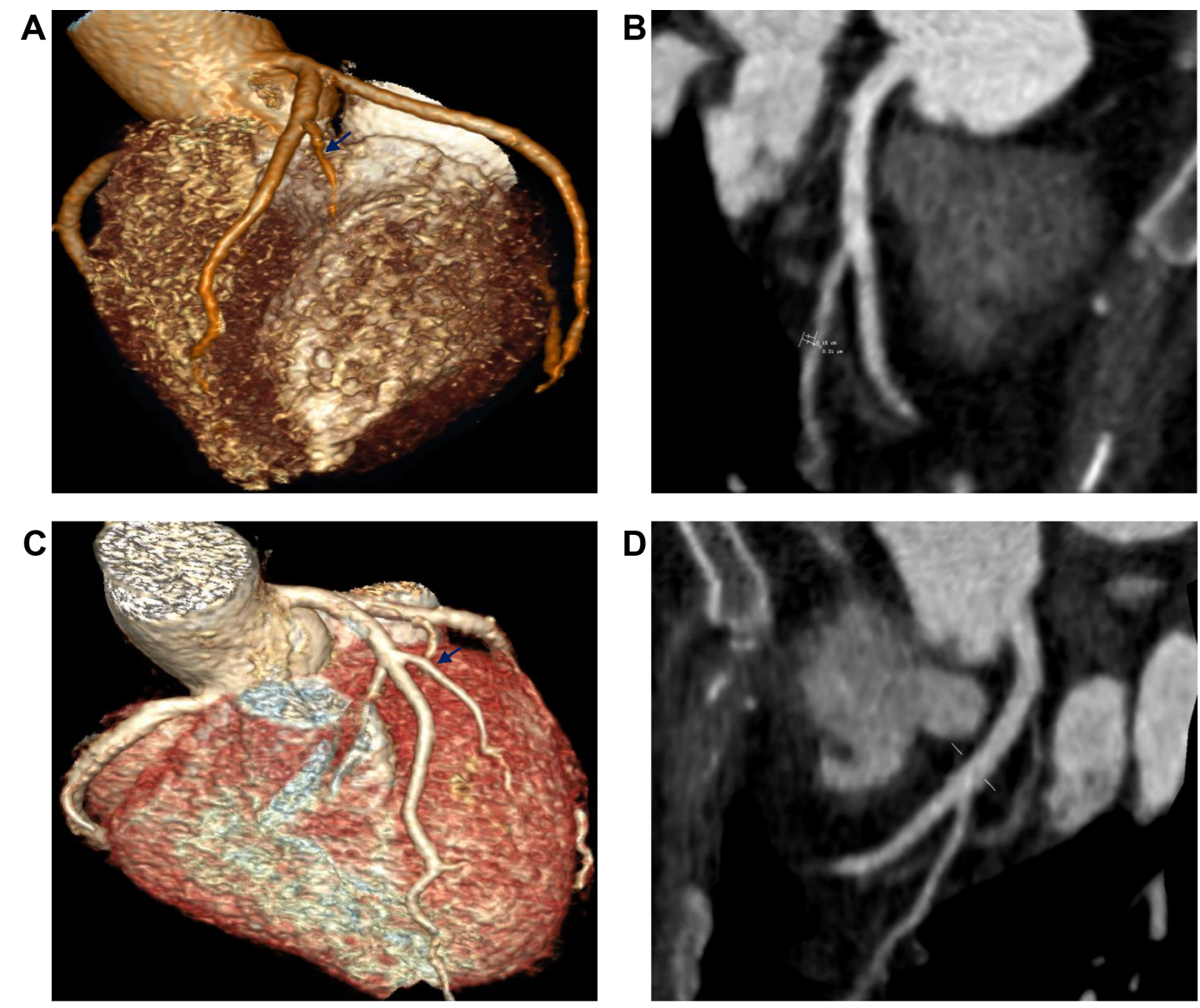

Figure I The coronary CT angiography of the patient.

Notes: Panels (A and B) show the first diagonal branch of the left coronary artery with approximately $50 \%$ stenosis, and the atherosclerotic plaque which was non-calcified prior to the treatment. Panels (C and D) show that the plaque in the first diagonal branch of left coronary artery disappeared after a I0-month Tongguan capsule treatment. The arrow in Figure I A indicates the stenosis. The arrow in Figure I C indicates the stenosis has disappeared. 
in total. The laboratory examination then showed that her LDL-C level was reduced to $1.83 \mathrm{mmol} / \mathrm{L}$, and non-HDL-C level reduced to $2.37 \mathrm{mmol} / \mathrm{L}$. A follow-up coronary CT scan showed that the coronary artery had normalized, with the plaque in her first diagonal branch of the left coronary artery having disappeared (Figure $1 \mathrm{C}$ and D).

\section{Discussion}

Compelling evidence shows that TCM is widely used for the treatment of numerous ailments and in the management of body functions, due to the various pharmacological properties, including its protective cardiovascular effect. ${ }^{13}$ To the best of our knowledge, this is the first case to report the significant plaque regression effect with the use of TGC on CHD patients.

In this case report, TGC showed a remarkable therapeutic effect on a patient with $\mathrm{CHD}$, evident from the regression of coronary atherosclerosis shown by coronary CT scans. This beneficial effect of TGC may be ascribed to the active components of the drug. There is evidence that $S$. miltiorrhiza possesses considerable protective cardiovascular effects through the regulation of oxidative stress, inflammatory responses, microcirculation, coronary vasodilatation, thromboxane formation, platelet adhesion and aggregation, and myocardial ischemia. ${ }^{8,10}$ Calycosin, the major bioactive component in the dry root extract of Radix astragali, exhibits a variety of properties in the treatment of inflammation, stroke, and CVD. ${ }^{14}$ There is increasing evidence which shows the beneficial actions of hirudin in the treatment of CVD. ${ }^{15,16}$ Furthermore, borneol shows antithrombotic, antioxidative, and anti-inflammatory effects in vivo. ${ }^{17,18}$ Taken together as TGC, these bioactive components all contributed to the therapeutic effect seen in the treatment of CHD in the patient. ${ }^{19}$

There was also a reduction in the level of LDL-C and non-HDL-C in the patient after the administration of TGC continuously for 10 months. It also improved acute coronary syndrome, and inhibited inflammation responses through the reduction of the high sensitivity-CRP levels. ${ }^{20,21}$ It is speculated that the lipid-lowering effect provides an explanation for the protective cardiovascular effect of TGC in our patient with CHD.

\section{Conclusion}

This case report shows that the administration of TGC exerted a therapeutic effect in a patient with CHD, evident from the remission of atypical chest discomfort, regression of coronary atherosclerosis, and reduction of LDL-C and non-HDL-C levels. These beneficial effects may be attributed to the pharmacologically active components of TGC, but further studies should be performed in order to understand these underlying mechanisms.

\section{Acknowledgment}

This work was supported by a grant (2011B032200006), from the Department of Science and Technology, Guangdong Provincial Academy of Medicine joint research projects, Guangdong, People's Republic of China.

\section{Disclosure}

The authors declare that there is no conflict of interest in this work.

\section{References}

1. Mozaffarian D, Benjamin EJ, Go AS, et al. Heart disease and stroke statistics - 2015 update: a report from the American Heart Association. Circulation. 2015;131(4):e29-e322.

2. Deaths: Final data for 2013. National Vital Statistics Report. 2015;64(2). Detailed tables released ahead of full report: Available from: http://www.cdc.gov/nchs/data/nvsr/nvsr64/nvsr64_02.pdf

3. World Health Organization [webpage on the Internet]. Cardiovascular diseases (CVDs); 2015 [updated January, 2015]. Available from: http:// www.who.int/mediacentre/factsheets/fs317/en/. Accessed May 20, 2015.

4. World Health Organization [webpage on the Internet]. Cardiovascular diseases. 2015 [cited May 20, 2015]; Available from: http://www. wpro.who.int/china/mediacentre/factsheets/cvd/en/. Accessed May 20, 2015.

5. Ling S, Dai A, Guo Z, et al. Effects of a Chinese herbal preparation on vascular cells in culture: mechanisms of cardiovascular protection. Clin Exp Pharmacol Physiol. 2005;32(7):571-578.

6. Zheng GH, Liu JP, Chu JF, et al. Xiongshao for restenosis after percutaneous coronary intervention in patients with coronary heart disease. Cochrane Database Syst Rev. 2013;5:CD009581.

7. Qiu Y, Xu H, Shi D. Traditional Chinese herbal products for coronary heart disease: an overview of Cochrane reviews. Evid Based Complement Alternat Med. 2012;2012:417387.

8. Cheng TO. Cardiovascular effects of Danshen. Int J Cardiol. 2007; 121(1):9-22.

9. Han XD, Zhou ZW, Yang W, et al. A computational and functional study elicits the ameliorating effect of the Chinese herbal formula Huo Luo Xiao Ling Dan on experimental ischemia-induced myocardial injury in rats via inhibition of apoptosis. Drug Des Dev Ther. 2015;9: $1063-1102$.

10. Zhou ZW, Xie XL, Zhou SF, Li CG. Mechanism of reversal of high glucose-induced endothelial nitric oxide synthase uncoupling by tanshinone IIA in human endothelial cell line EA.hy926. Eur J Pharmacol. 2012; 697(1-3):97-105.

11. Ramsey SD. Aspirin, clopidogrel, or both for secondary prevention of coronary disease. $N$ Engl J Med. 2003;348(6):560-563.

12. Sandhofer F. [Statins in secondary prevention of coronary heart disease]. Wien Med Wochenschr. 1999;149(5-6):125-128.

13. Alherbish A, Charrois TL, Ackman ML, et al. The prevalence of natural health product use in patients with acute cardiovascular disease. PLoS One. 2011;6(5):e19623.

14. Gao J, Liu ZJ, Chen T, et al. Pharmaceutical properties of calycosin, the major bioactive isoflavonoid in the dry root extract of Radix astragali. Pharm Biol. 2014;52(9):1217-1222.

15. Cheng-Lai A. Cardiovascular drug highlight: hirudin. Heart Dis. 1999; 1(1):41-49. 
16. Alexander B, Burnand KG, Lattimer CL, et al. The effect of anticoagulation with subcutaneously delivered polyethylene glycol conjugated hirudin and recombinant tissue plasminogen activator on recurrent stenosis in the rabbit double-balloon injury model. Thromb Res. 2004;113(2):155-161.

17. Li YH, Sun XP, Zhang YQ, Wang NS. The antithrombotic effect of borneol related to its anticoagulant property. Am J Chin Med. 2008;36(4): 719-727.

18. Wu HY, Tang Y, Gao LY, et al. The synergetic effect of edaravone and borneol in the rat model of ischemic stroke. Eur J Pharmacol. 2014; 740:522-531.
19. Xiaoyan Zhang GS. The effect of Tongguan capsule to treat hyperlipemia. Natl Med Front Chin. 2011;6(14):27-28. Chinese.

20. Banghan Ding JC, Zhou X, Li S, Zhang M. The effect of Tongguan capsule on the hs-CRP level of acute coronary syndrome patients. J Guangzhou Univ Tradit Chin Med. 2012;27(2):110-111.

21. Qi J, Ren Y, Wang L, Guo L, Wu J, Zhang M. 6-year post-PCI follow-up of a 110-year myocardial infarction patient: a case report. Int J Cardiol. 2014;176(3):e119-e121.

\section{Publish your work in this journal}

Drug Design, Development and Therapy is an international, peerreviewed open-access journal that spans the spectrum of drug design and development through to clinical applications. Clinical outcomes, patient safety, and programs for the development and effective, safe, and sustained use of medicines are a feature of the journal, which has also been accepted for indexing on PubMed Central. The manuscript management system is completely online and includes a very quick and fair peer-review system, which is all easy to use. Visit http://www.dovepress.com/testimonials.php to read real quotes from published authors.

Submit your manuscript here: http://www.dovepress.com/drug-design-development-and-therapy-journal 